Article

\title{
Quantitative Responses of Satellite-Derived Nighttime Lighting Signals to Anthropogenic Land-Use and Land-Cover Changes across China
}

\author{
Ting Ma ${ }^{1,2,3}$ (D) \\ 1 State Key Laboratory of Resources and Environmental Information System, Institute of Geographical \\ Sciences and Natural Resources Research, Chinese Academy of Sciences, Beijing 100101, China; \\ mting@lreis.ac.cn; Tel.: +86-10-64889769 \\ 2 University of Chinese Academy of Sciences, Beijing 100049, China \\ 3 Jiangsu Center for Collaborative Innovation in Geographical Information Resource Development and \\ Application, Nanjing 210023, China
}

Received: 4 August 2018; Accepted: 7 September 2018; Published: 11 September 2018

\begin{abstract}
Remotely sensed artificial lighting radiances at night can provide spatially explicit proxy measures of the magnitude of human activity. Satellite-derived nighttime light images, mainly provided by the Defense Meteorological Satellite Program (DMSP) and the Visible Infrared Imaging Radiometer Suite (VIIRS) day/night band (DNB), have been increasingly used to study demographic and socioeconomic activities for a wide range of issues-for instance, human population dynamics, economic growth, and urbanization process-at multiple scales. In practice, the lack of texture information regarding man-made surfaces would usually lead to substantial difficulty in delineating the spatial dynamics in human settlements due to the diverse distributions of artificial nocturnal lighting sources, which are closely related to the predominant land-use/land-cover (LULC) types and their evolutions. An understanding of how nighttime lighting signals respond to synchronous anthropogenic LULC changes, therefore, is crucially important for the spatiotemporal investigations of human settlement dynamics. In this study, we used DMSP-derived nighttime light (NTL) data and Landsat-derived LULC maps to quantitatively estimate the pixel-level responses of NTL signals to different types of human-induced LULC conversions between 1995 and 2010 across China. Our results suggest that the majority $(>70 \%)$ of pixel-level LULC conversions into artificial lands (including urban, rural, and built-up lands) might show a statistically significant increase in nighttime brightness with an average $>20$ (in digital number, DN) step change in nighttime lights (dNTL), both of which are distinctly higher than that in the LULC conversions into non-man-made surfaces on the whole. A receiver operating characteristic (ROC) curve-based analysis implies that we might have an average chance of $\sim 90 \%$ to identify the nationwide LULC conversions into man-made surfaces from all types of conversions through the observed changes in artificial nocturnal luminosity signals. Moreover, ROC curve-based analyses also yield two nation-level optimal dNTL thresholds of 4.8 and 7.8 DN for recognizing newly emerged three types of artificial lands and urban lands between 1995 and 2010 across the entire country, respectively. In short, our findings reveal fundamental insights into the quantitative connections between the anthropogenic LULC changes and the corresponding responses of synchronous nightlight signals at the pixel-level, which are generally essential for further applications of satellite-derived nocturnal luminosity data in the spatiotemporal investigations of human settlement dynamics.
\end{abstract}

Keywords: nighttime light; land-use/land-cover change; step change; artificial lands; optimal threshold 


\section{Introduction}

Satellite-based observations of artificial nocturnal brightness have been extensively used for a range of issues related to human activity because of the well-documented significant relationships between nighttime lighting (NTL) signals and several urbanization, demographic, and socioeconomic variables over time and space [1-10]. The outstanding characteristic of remotely sensed nighttime light datasets is that they can provide us with timely and consistent proxy measures of the degrees of various human activities in a spatially explicit manner [11-15] closely related to land features [16]. The widely used nighttime light images were previously provided by the Defense Meteorological Satellite Program (DMSP) and are currently being derived from the Visible Infrared Imaging Radiometer Suite (VIIRS) day/night band (DNB) onboard the Suomi National Polar-Orbiting Partnership (Suomi-NPP) satellite [17-21]. Both satellite-derived observations show significant quantitative responses of sensed nighttime light radiances to gross domestic product, human population size, urbanized areas, and electric power consumption at local, regional, and national scales [22-33].

Compared with visible or infrared remote sensing images representing the spatial patterns of natural and man-made land features, satellite-derived nighttime light data are primarily determined by the spatial distributions of artificial lighting sources at night. Thus, the lack of detailed texture information regarding landscape features poses a major challenge to characterizing the spatial and temporal patterns in human settlements [34]. Moreover, the saturation (for DMSP data due to the lack of on-board radiance calibration) and over-glow (i.e., pixels can be lighted by adjacent lighting sources, for both DMSP and VIIRS DNB data) effects of nightlight signals can markedly affect the spatial identifications of artificial land features [25,31,34]. In practice, satellite-derived land-use and land-cover maps and vegetation index data have typically been applied in nighttime light data-based studies to diminish the impacts of the abovementioned effects and improve the recognition accuracy of man-made surfaces across human settlements [35-37].

Although the combination of nighttime light data and other sources of remote sensing data can be helpful for studying human activity in terms of the magnitude and its spatial patterns, the spatial partition of human settlements is still challenging, largely because of both the diversity of human activity and the spatial heterogeneity of artificial lighting sources at night, even though we have more detailed looks as provided by the current VIIRS DNB images. Hence, an understanding of the connection between nighttime lights and corresponding land features and how nightlight signals respond to anthropogenic land-use and land-cover (LULC) changes at the pixel level is crucial for further applications of remotely sensed nocturnal luminosity data. Unfortunately, despite their fundamental importance, these two issues are less well understood.

Using VIIRS DNB nighttime light data and Landsat-derived LULC maps, our previous study [16] has represented a nationwide investigation with respect to the pixel-level relationship between NTL and various types of LULC across China. In the present study, we aim for the quantitative responses of nighttime lighting signals to corresponding anthropogenic LULC changes between 1995 and 2010 in China. DMSP-derived NTL data and Landsat-derived LULC data are used to perform a nationwide comparative analysis of the pixel-level alterations in nighttime lights between the two observational periods among different types of human-induced LULC conversions. Welch's $t$-test is employed to examine whether there exists a statistically significant step change in the pixel-level NTL signals in response to synchronous LULC conversions. This study, together in association with our previous investigation [16], represents an attempt to provide a basic understanding of the connections between two satellite-based observations of nocturnal light radiances and the LULC types and their synchronous alterations for further applications of nighttime light data in studies of human settlement dynamics. 


\section{Materials and Methods}

\subsection{Land-Use and Land-Cover Data}

Two LULC maps with a spatial resolution of $100 \mathrm{~m}$ under the Albers equal-area projection across China's mainland in 1995 and 2010 were provided by the Institute of Geographical Sciences and Natural Resource Research (IGSNRR) [38]. These LULC datasets were derived from Landsat Thematic Mapper (TM) and Enhanced Thematic Mapper Plus (EMT+) images and produced by using a supervised classification method in cooperation with ground truth verification. Detailed information regarding the LULC data can be found in [38,39]. In this study, the LULC types initially presented in the IGSNRR maps were re-categorized into seven different categories: cropland (including rain-fed and irrigated), vegetation (including grassland and forestland), water (consisting of rivers, lakes, reservoirs, and bottomland), urban land (settlements), rural land (residential areas, including small towns, villages, and hamlets), built-up land (consisting of industrial areas, factories, mines, oil fields, salt fields, and transportation), and unused land (consisting of deserts, Gobi, swamps, and bare soil). As exemplified by the Pearl River Delta, there are visible LULC conversions into human-dominated lands between 1995 and 2010 (see Figure 1a,b), mainly driven by the underlying rapid economic growth and urbanization process in this region and across the entire country as well. A total of $12,210,817$ pixels (covering $12.2 \times 10^{4} \mathrm{~km}^{2}$ of land surface) appear to have LULC changes between 1995 and 2010 across China and are thus involved in subsequent analyses.

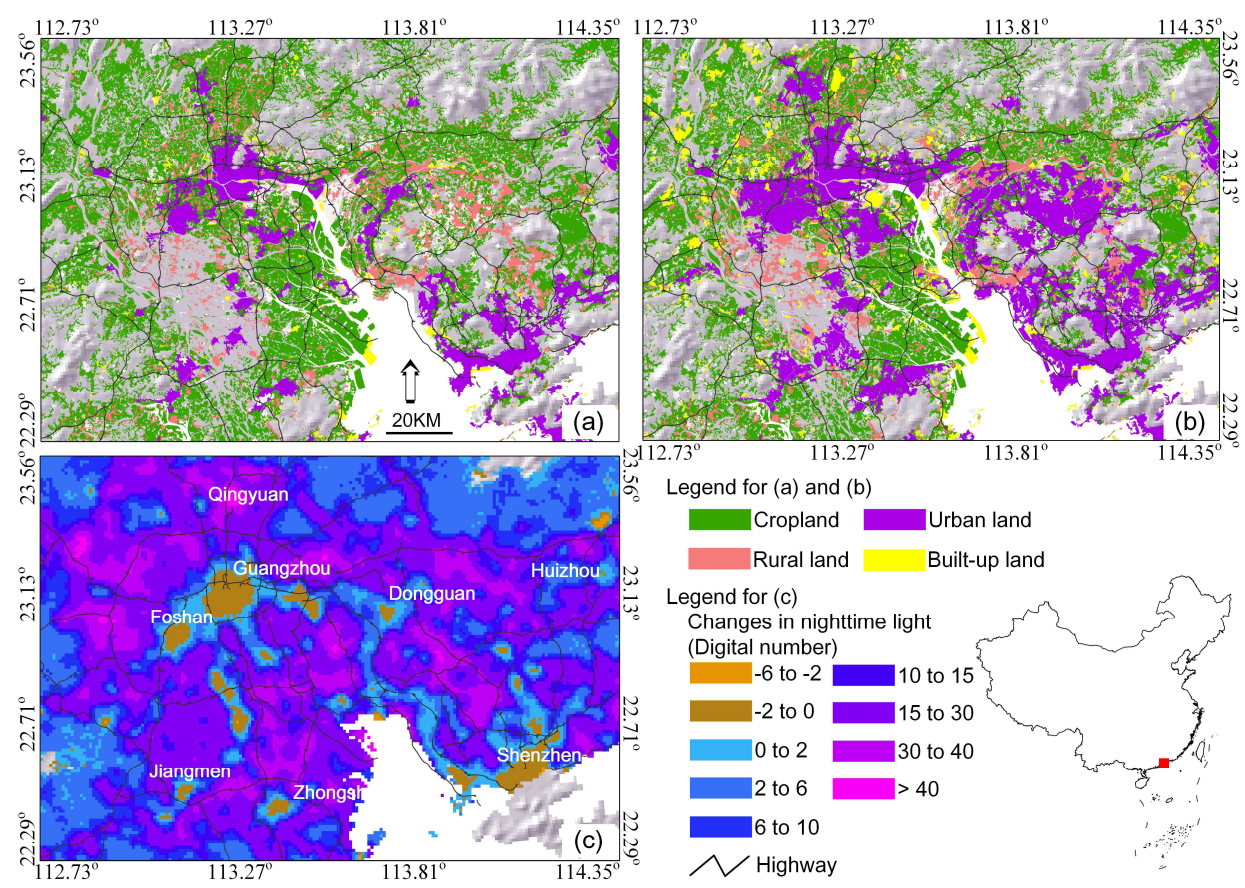

Figure 1. Illustrations of satellite-derived observations of anthropogenic land-use/land-cover (LULC) changes and synchronous dynamics in nighttime lighting (NTL) signals over the Pearl River Delta region in China. (a) Landsat-derived human-dominated land uses in 1995. (b) Landsat-derived human-dominated land uses in 2010. (c) The Defense Meteorological Satellite Program (DMSP)-derived average NTL changes between 1992-1995 and 2010-2013.

\subsection{Nighttime Light Brightness Data}

Time-series data of annual cloud-free composited stable DMSP nighttime light products (version 4.0) for the period 1992-1995 and the period 2010-2013 were used in this study. DMSP NTL images with a spatial resolution of 30 arc-seconds under the WGS84 spatial reference system $(\sim 1 \mathrm{~km}$ at the equator and $\sim 0.8 \mathrm{~km}$ at $40^{\circ} \mathrm{N}$ ) were provided by the National Oceanic and Atmospheric Administration (NOAA) National Centers for Environmental Information (NCEI) (we downloaded 
the data from the website at https://ngdc.noaa.gov/eog/dmsp.html). DMSP NTL images were re-projected into the Albers equal-area projection by a nearest neighbor resampling method to match the LULC datasets. Original DMSP NTL images are composed of the annual average visible band digital numbers (DN, hereafter) ranging from 0 to 63. To diminish the yearly variations and differences among sensors, the second-order regression model proposed by [40] was used to empirically intercalibrate the DMSP NTL products. Moreover, the annual composites of DMSP NTL images that show the best fitting regression for years with two separate sensor composites were used in this study (here, F10 was used for 1992-1994, F12 for 1995 and F18 for 2010-2013). As demonstrated in Figure 1c, the four-year mean of DMSP NTL signals shows marked changes accompanying the LULC conversions (see Figure 1a,b), prevalent over the Pearl River Delta, between the two observational periods. Hence, we would be able to estimate the pixel-level responses of DMSP NTL signals to corresponding LULC changes.

\subsection{Step Change in Nighttime Light Signals}

Theoretically, anthropogenic LULC conversions usually accompany alterations in artificial nighttime lighting sources, especially with respect to man-made surfaces. Hence, such changes can be captured by satellite-derived measurements of nocturnal brightness. Figure 2a illustrates the observed changes in DMSP NTL during 1992-1995 and 2010-2013 over a given LULC pixel, which was recognized as cropland in 1995 and converted into urban land in 2010. For quantifying the response of nightlight signals to corresponding LULC changes, we defined the step change in DMSP NTL (termed dNTL throughout, in units of DN) as the difference between the four-year arithmetic means of 2010-2013 and 1992-1995. We use here the four-year mean instead of that of a single year in an attempt to reduce the effect of inter-annual variations and uncertainty in DMSP NTL signals and further to allow us to perform the statistical test on the mean change in NTL signals responding to the LULC conversions. In the present study, the two-sided Welch's $t$-test (also known as the unequal variances $t$-test) was used to test the statistical significance of dNTL based on the null hypothesis (H0) that two observed time series of DMSP NTL data have equal means (i.e., $\mathrm{dNTL}=0$ ). In subsequent analyses, we mainly use the average dNTL and the proportion of converted pixels showing statistically significant dNTL $(P$-value $<0.05)$ at the pixel-level to estimate the response of DMSP NTL signals to different types LULC conversions. Moreover, we use a receiver operating characteristic (ROC) curve to obtain optimal dNTL thresholds for identifying LULC conversions into artificial lands. The flow chart for the study is presented in Figure 2b. Data processing and analyses were performed in Esri's ArcGIS and the R software environments.

(a) 60

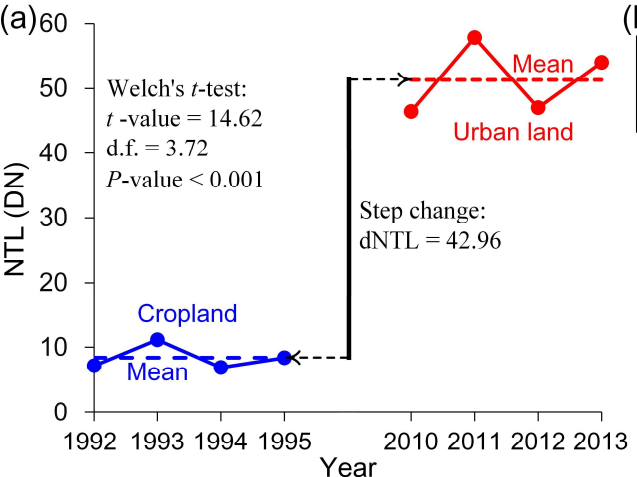

(b)

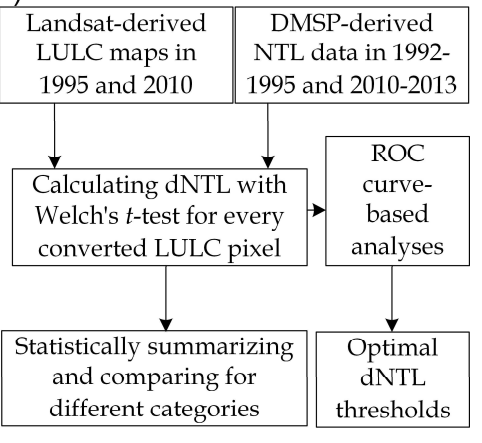

Figure 2. (a) An illustrative example of observed changes in nighttime light (NTL) over a given pixel converted from cropland (1995) into urban land (2010) between 1992-1995 and 2010-2013. Welch's $t$-test indicates that there is a statistically significant step change in nighttime lighting signals (dNTL) between the two observational periods. (b) Flow chart of the study. 


\section{Results and Discussion}

\subsection{LULC Changes and Nightlight Dynamics}

Driven by the fast-growing economy and rapid urbanization process, China appears to have undergone remarkable changes in the nationwide LULC over the past several decades [39]. As represented in Figure 3a, human activity contributes the majority of the LULC conversions between 1995 and 2010. Most notably, sizeable pixels $\left(\sim 75.9 \%\right.$ of the total 10,452,217, $\sim 7.9 \times 10^{4} \mathrm{~km}^{2}$, after excluding minor types of LULC conversions, hereafter) were found to be converted into human-dominated lands (including croplands, urban lands, rural lands, and built-up lands) from vegetation, water, and unused lands. Approximately $88.7 \%$ of LULC conversions were related to croplands $\left(\sim 4.5 \times 10^{4} \mathrm{~km}^{2}\right) . \sim 21.7 \%$ of pixels $\left(\sim 2.3 \times 10^{4} \mathrm{~km}^{2}\right)$ were converted into human settlements (including urban and rural) and built-up lands. It is should be mentioned that some types of LULC conversions with a pixel number less than $10^{4}$ were excluded from Figure 3 a because these minor conversions typically occurred among non-man-made surfaces with dim nighttime lighting signals.

(a)

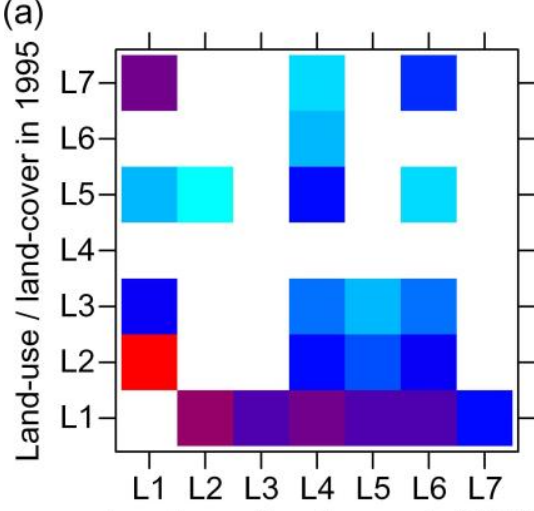

Land-use / land-cover in 2010

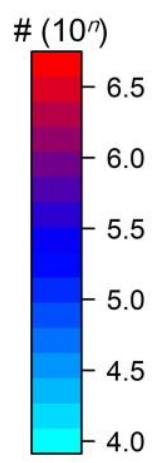

4.0

L1-Cropland L2-Vegetation L3-Water L4-Urban land (b)

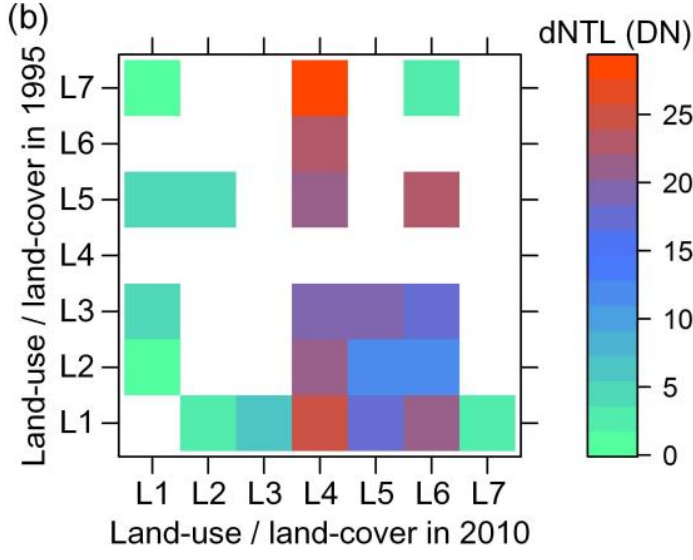

Figure 3. (a) Summary of the pixel number for major kinds of LULC conversions between 1995 and 2010 in China. (b) Average step change in nighttime lighting signals between 1992-1995 and 2010-2013 for corresponding kinds of LULC conversions.

As exhibited in Figure 3b, all types of LULC conversions likely show increased nighttime light radiances on average. In general, the LULC conversions into artificial lands, including urban, rural and built-up lands (except the unused-to-built-up conversion), show a distinctly higher average step change in DMSP NTL between 1992-1995 and 2010-2013 than those in other types of LULC conversions. The most notable step change in DMSP NTL occurred in the LULC conversions into urban lands with a mean of $23.2 \pm 12.4$ (standard deviation, SD). In particular, a relatively large average of dNTL was found in both the cropland-to-urban $(24.1 \pm 12.4)$ and unused-to-urban $(27.6 \pm 12.4)$ conversions. The LULC conversions among non-man-made surfaces-including croplands, vegetation, water, and unused lands-commonly show a slightly increase in NTL, which is generally less than 6.0 (estimated for the cropland-to-water conversion). Overall, these results clearly indicate measurable alterations in nighttime light data in response to the human-induced LULC changes, especially for the LULC conversions into artificial lands. In the following sections, we mainly pay attention to detailed statistical comparisons of dNTL for three major categories of anthropogenic LULC changes, including the conversions from croplands, vegetation, and rural lands into other types of LULC.

\subsection{Statistical Comparisons of dNTL for the LULC Conversions from Croplands}

A total of $\sim 4.5$ million cropland pixels $\left(\sim 4.5 \times 10^{4} \mathrm{~km}^{2}\right)$ have been converted into other types of LULC between 1995 and 2010 across the entire country, of which $35.2 \%\left(\sim 1.6 \times 10^{4} \mathrm{~km}^{2}\right)$ and $49.3 \%$ 
$\left(\sim 2.2 \times 10^{4} \mathrm{~km}^{2}\right)$ were changed into vegetation and man-made lands, respectively (see Figure 4a). The former major conversion from croplands likely resulted from the reforestation of the cultivated lands, and the latter was driven by the epic urbanization process since the end of 1990's in China [39]. Figure $4 \mathrm{~b}$ displays the density distribution of dNTL for different types of LULC conversions from croplands. Most obviously, the overall response of NTL signals to the LULC conversions from croplands into three types of artificial lands (median $=24.7$ with 1 st-3rd quartile $=14.8-33.5$ for urban lands, 14.3 with 4.4-30.8 for rural lands, and 21.4 with 8.0-33.5 for built-up lands) are generally much higher than those in other types of the LULC conversions. $88.8 \%\left(\sim 0.9 \times 10^{4} \mathrm{~km}^{2}\right)$, $76.7 \%\left(\sim 0.5 \times 10^{4} \mathrm{~km}^{2}\right)$, and $86.7 \%\left(\sim 0.4 \times 10^{4} \mathrm{~km}^{2}\right)$ of pixels show statistically significant dNTL $(P$-value $<0.05)$ in the conversions into urban lands, rural lands, and built-up lands, respectively (Figure $4 \mathrm{e}, \mathrm{f}, \mathrm{g}$ ). In contrast, a major proportion of pixels in other types of LULC conversions show no statistically significant increases in NTL signals (i.e., $P$-value $>0.05$ or $\mathrm{dNTL} \leq 0$, here $84.8 \%$ $\left(\sim 1.4 \times 10^{4} \mathrm{~km}^{2}\right)$ for vegetation, $57.9 \%\left(\sim 0.1 \times 10^{4} \mathrm{~km}^{2}\right)$ for water and $83.3 \%$ for unused lands) (see Figure $4 c, d, h$ ).
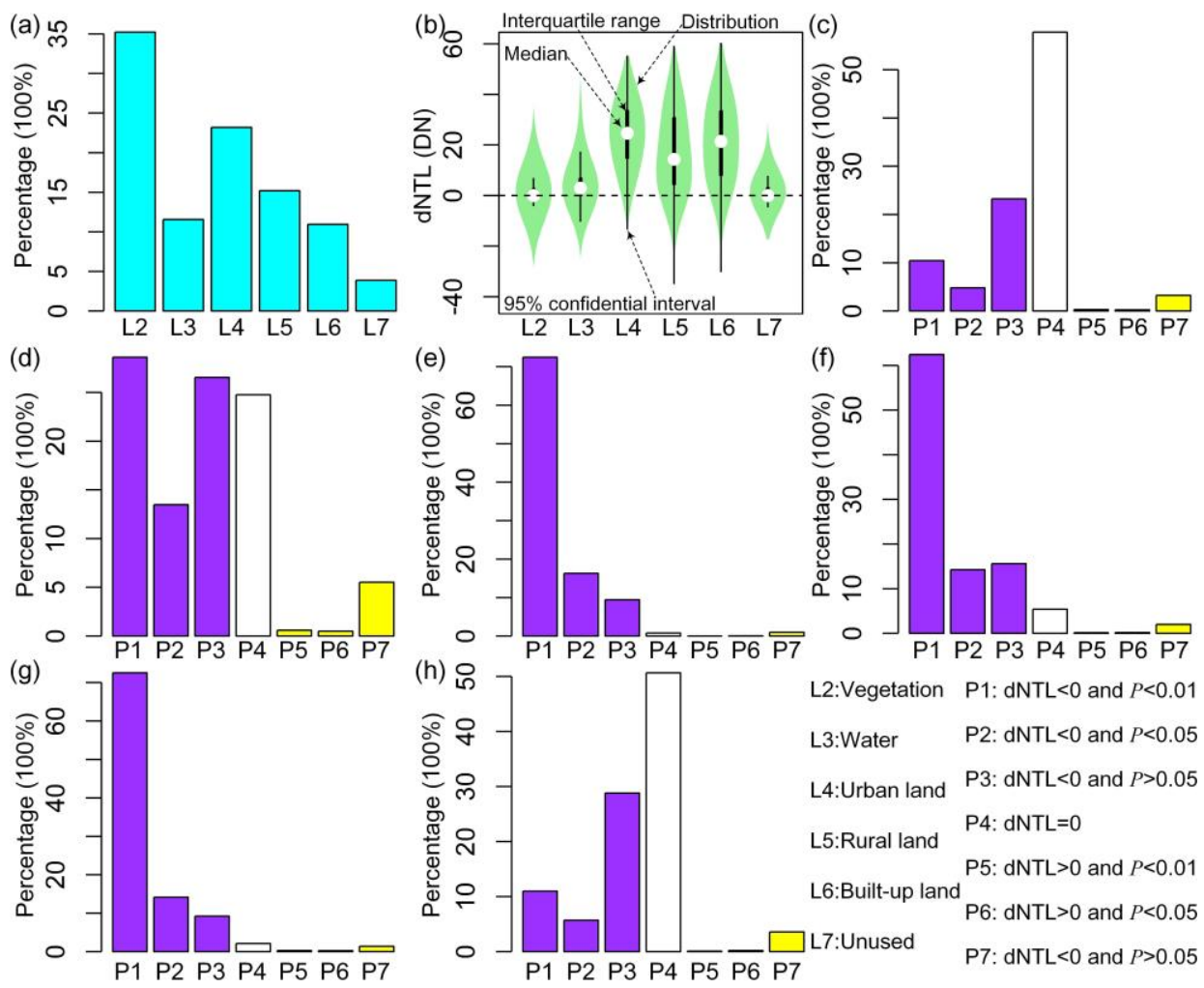

Figure 4. Statistical results of the pixel-level step change in nighttime light signals for LULC conversions from croplands into other types of lands between 1995 and 2010. (a) Relative proportions of different types of LULC pixels converted from croplands. (b) Density distributions of dNTL. (c-h) Analyzed results of Welch's $t$-test for dNTL of LULC changes from croplands converted into (c) vegetation, (d) water, (e) urban lands, (f) rural lands, (g) built-up lands, and (h) unused lands, respectively.

\subsection{Statistical Comparisons of dNTL for the LULC Conversions from Vegetation}

Between 1990 and 2010, 4.3 million pixels $\left(\sim 4.3 \times 10^{4} \mathrm{~km}^{2}\right)$ were found to be converted from natural vegetation into croplands (accounting for $87.9 \%$ of the total converted vegetation pixels, $\sim 3.8 \times 10^{4} \mathrm{~km}^{2}$ ) and artificial surfaces $\left(12.1 \%, \sim 0.5 \times 10^{4} \mathrm{~km}^{2}\right.$ ) (Figure 5a). Over the past two decades, the LULC conversions from forestlands and grasslands into croplands mainly occurred in Northeast and Northwest China due to notably increased agricultural activities in these two regions [39]. On the whole, no visible changes in NTL signals (0.0 with $0.0-1.6)$ were found in the LULC conversions 
from vegetation into croplands (Figure $5 \mathrm{~b}$ ), in which merely $11.5 \%$ of pixels $\left(\sim 0.4 \times 10^{4} \mathrm{~km}^{2}\right)$ shows a statistically significant, but very slight, increase in nighttime light brightness between 1990 and 2010 (Figure 5c). The most marked average change in NTL signals appears to occur in the conversions of vegetation into urban lands (20.6 with 10.7-29.6), in which most pixels $\left(83.7 \%, \sim 0.1 \times 10^{4} \mathrm{~km}^{2}\right.$ ) show a significant positive change in NTL signals (Figure 5c). Two types of conversions, from vegetation into both rural lands and built-up lands, show closely similar dNTL (5.5 with 0-19.0 vs. 6.6 with 1.3-19.0, and $52.4 \%$ vs. $61.4 \%$ of pixels showing $\mathrm{dNTL}>0$ and $P$-value $<0.05, \sim 0.05 \times 10^{4}$ and $0.1 \times 10^{4} \mathrm{~km}^{2}$, respectively) (see Figure $5 b, e, f)$.
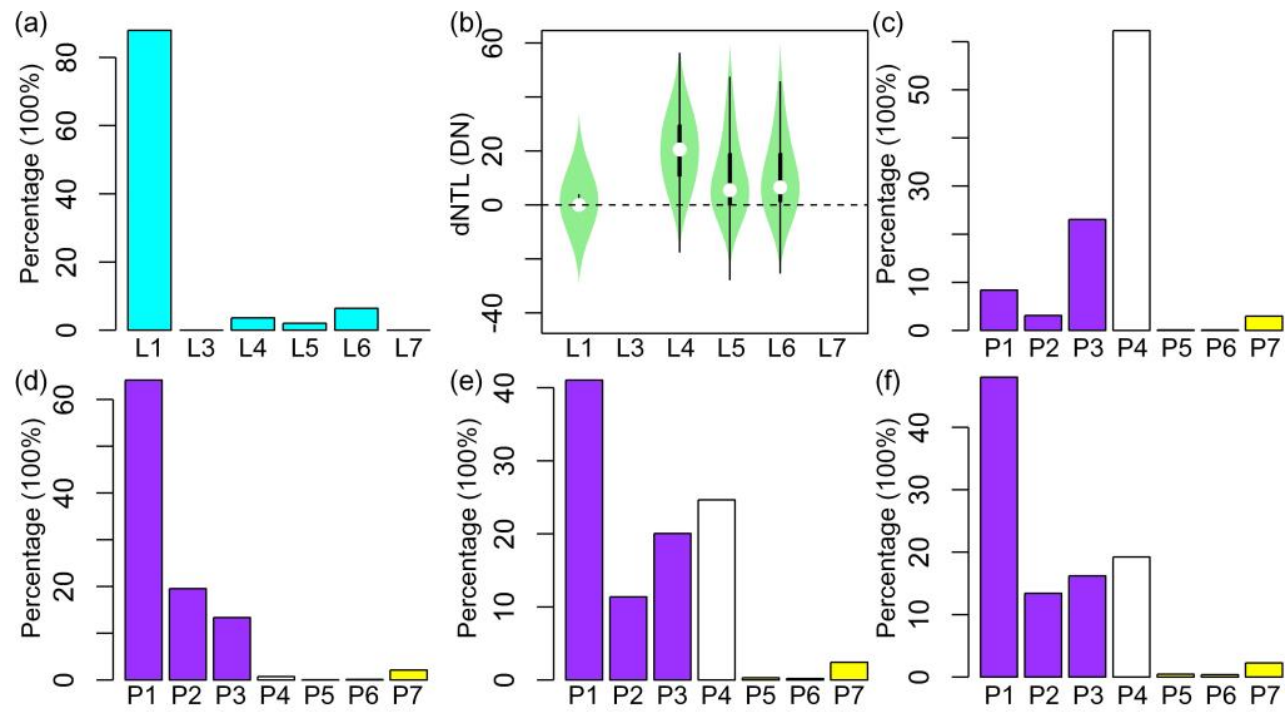

L1:Cropland L3:Water L4:Urban land L5:Rural land L6:Built-up land

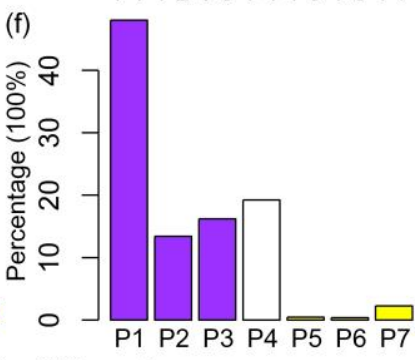

$\mathrm{P} 1: \mathrm{dNTL}<0$ and $P<0.01 \quad \mathrm{P} 2: \mathrm{dNTL}<0$ and $P<0.05 \quad \mathrm{P} 3: \mathrm{dNTL}<0$ and $P>0.05 \quad \mathrm{P} 4: \mathrm{dNTL}=0 \quad \mathrm{P} 5: \mathrm{dNTL}>0$ and $P<0.01$

P6: $\mathrm{dNTL}>0$ and $P<0.05 \mathrm{P} 7: \mathrm{dNTL}<0$ and $P>0.05$

Figure 5. Statistical results of the pixel-level step change in nighttime light signals for LULC conversions from vegetation into other types of lands between 1995 and 2010. (a) Relative proportions of different types of LULC pixels converted from croplands. (b) Density distributions of dNTL. (c-f) Analyzed results of Welch's $t$-test for dNTL of LULC changes from vegetation converted into (c) croplands, (d) urban lands, (e) rural lands, and (f) built-up lands, respectively.

\subsection{Statistical Comparisons of dNTL for the LULC Conversions from Rural Land}

Diverse human activities and several land-use policies (e.g., urban expansion, rural exodus and hollowing, and consolidation of rural lands) can lead to the conversions of rural lands into other types of LULC in present-day China [41,42]. As shown in Figure $6 \mathrm{a}, 76.4 \%\left(\sim 0.17 \times 10^{4} \mathrm{~km}^{2}\right)$ and $12.2 \%\left(\sim 0.02 \times 10^{4} \mathrm{~km}^{2}\right)$ of initial rural pixels (a total of $\sim 0.2$ million, $\sim 0.2 \times 10^{4} \mathrm{~km}^{2}$ ) have become urban lands and croplands, respectively, between 1995 and 2010 with the rapid urbanization process and increasing rural depopulation [41]. Meanwhile, the remaining 5.4\% $\left(\sim 0.01 \times 10^{4} \mathrm{~km}^{2}\right)$ and $6.0 \%\left(\sim 0.01 \times 10^{4} \mathrm{~km}^{2}\right)$ of initial rural lands have been converted into vegetation and built-up lands, respectively. Conversions into both urban lands and built-up lands commonly show a notable average dNTL (21.9 with 11.8-31.3 and 24.0 with 12.2-34.1, respectively) (Figure 6b). Correspondingly, the statistically significant positive step change in NTL signals was found over $85.8 \%\left(\sim 0.1 \times 10^{4} \mathrm{~km}^{2}\right)$ and $88.9 \%\left(\sim 0.01 \times 10^{4} \mathrm{~km}^{2}\right)$ of converted pixels in these two types of LULC conversions (Figure 6e,f). On the whole, no remarkable changes in NTL signals have been observed for the LULC conversions from rural lands into both croplands and natural vegetation with respect to the distribution of dNTL (Figure $6 \mathrm{~b}$ ) and the proportions of converted pixels with a statistically marked step change in NTL signals (Figure 6c,d). 

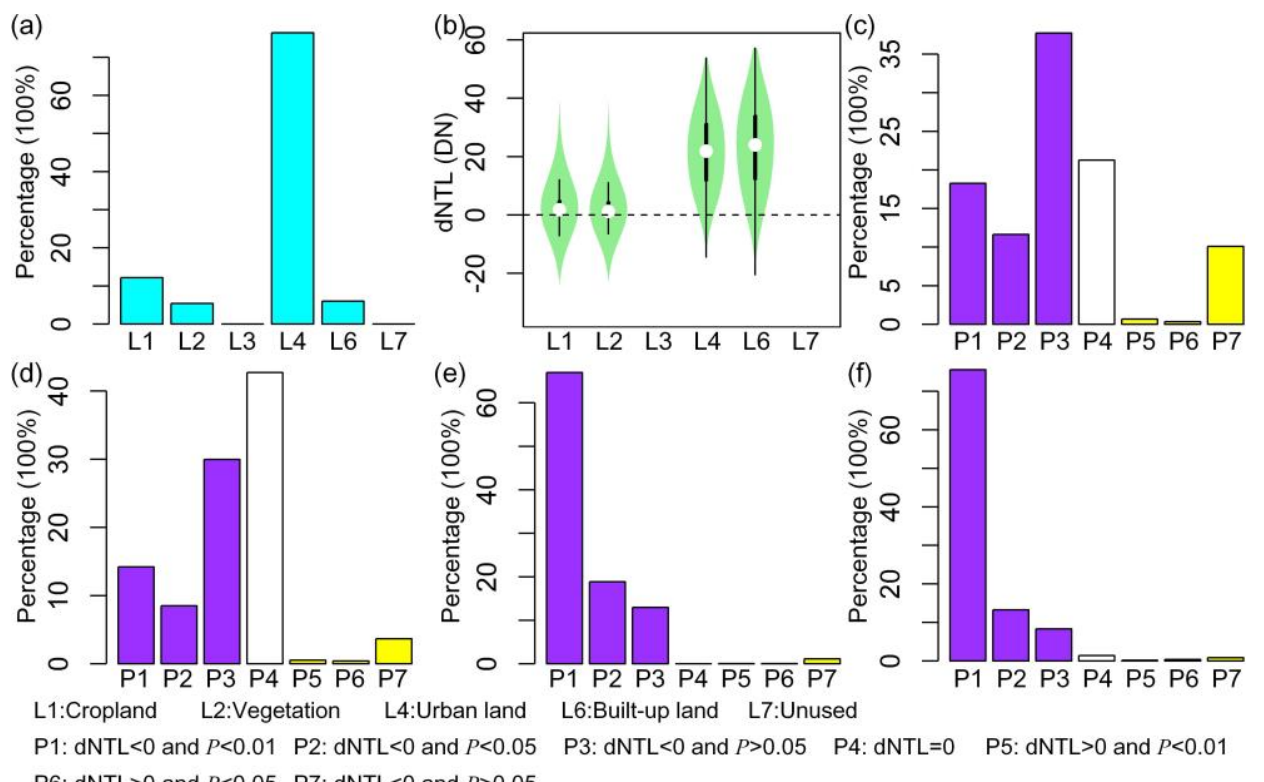

Figure 6. Statistical results of the pixel-level step change in nighttime light signals for LULC conversions from rural lands into other types of lands between 1995 and 2010. (a) Relative proportions of different types of LULC pixels converted from croplands. (b) Density distributions of dNTL. (c-f) Analyzed results of Welch's $t$-test for dNTL of LULC changes from rural lands converted into (c) croplands, (d) vegetation, (e) urban lands, and (f) built-up lands, respectively.

\subsection{Statistical Comparisons of dNTL among Different Types of Newly Emerged Lands}

The above results jointly gave the descriptive summaries of quantitative responses of nighttime lighting brightness to corresponding anthropogenic LULC changes across China with a focus on three major categories of the LULC conversions from croplands, vegetation, and rural lands. Next, we pay attention to statistical comparisons of the step change in nighttime lights among different types of newly emerged lands converted from other types between 1995 and 2010. First, our results suggest that most of the pixels converted into artificial lands $(87.7,74.1$, and $70.6 \%$ for urban lands, rural lands, and built-up lands, $\sim 1.3 \times 10^{4}, 0.6 \times 10^{4}$, and $0.7 \times 10^{4} \mathrm{~km}^{2}$, respectively) likely have a marked step change in NTL signals (dNTL $>0$ and $P$-value $<0.05)$ (Figure 7a). $42.1 \%\left(\sim 0.2 \times 10^{4} \mathrm{~km}^{2}\right)$ of the pixel-level conversions into water show significant nightlight responses largely because of increased human activities locally or in adjacent settlement/built-up areas. Such effects might also contribute enhanced nighttime light radiances for few proportions of the LULC conversions into croplands and other non-human-dominated lands. Second, as exhibited in Figure $7 \mathrm{~b}$, the statistically significant $(P$-value $<0.05)$ positive step change in NTL signals was found across a total of $\sim 3.7$ million converted pixels $\left(\sim 3.7 \times 10^{4} \mathrm{~km}^{2}\right)$, in which the majority $\left(69.6 \%, \sim 2.6 \times 10^{4} \mathrm{~km}^{2}\right)$ were likely converted into man-made surfaces, including urban lands $\left(34.9 \%, \sim 1.3 \times 10^{4} \mathrm{~km}^{2}\right)$, rural lands $\left(16.2 \%, \sim 0.6 \times 10^{4} \mathrm{~km}^{2}\right)$, and built-up lands $\left(18.4 \%, \sim 0.7 \times 10^{4} \mathrm{~km}^{2}\right)$. Third, in spite of the statistical significance, there are distinct differences in the distributions of the pixel-level net increases in NTL signals among different LULC conversions into man-made lands and other types of lands (see Figure 7c). The median is estimated to be larger than 22.0 commonly for the LULC conversions into three types of artificial lands, while the median and the third quartile are typically less than 8.1 and 18.3, respectively, for the LULC conversions into other types of non-man-made lands. Moreover, there are visible intercity differences in dNTL with respect to LULC conversions into urban lands among 10 major cities (Table 1), probably because of the variations in the city form. 


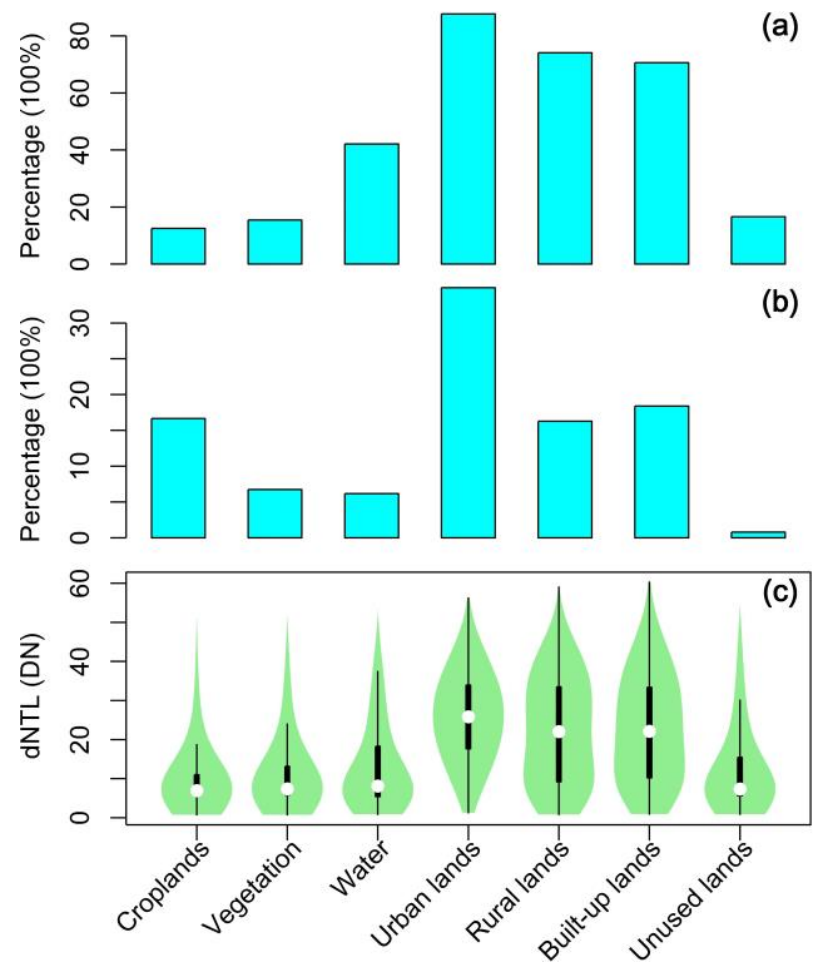

Figure 7. (a) LULC type-specific percentages of pixels with significant positive dNTL $(P$-value $<0.05)$ converted from other types between 1995 and 2010. (b) Relative proportions of pixels showing significant positive dNTL $(P$-value $<0.05)$ and converted into different types of LULC between 1995 and 2010. (c) Density distributions of the pixel-level positive dNTL with $P$-value $<0.05$ for different types of LULC converted from other types between 1995 and 2010.

Table 1. Summary of the pixel-level step change in nighttime light signals (dNTL) for LULC conversions into urban lands between 1995 and 2010 across 10 major cities in China.

\begin{tabular}{cccccccc}
\hline \multirow{2}{*}{ City } & \multirow{2}{*}{ C1 } & \multirow{2}{*}{ C2 } & \multirow{2}{*}{ C3 } & \multicolumn{4}{c}{ dNTL } \\
\cline { 5 - 8 } & & & & C4 & C5 & C6 & C7 \\
\hline Guangzhou & 403.3 & 806.1 & 402.8 & 13.71 & 5.75 & 21.87 & 80.22 \\
Beijing & 1017.0 & 1404.6 & 387.6 & 21.34 & 12.95 & 28.28 & 85.12 \\
Suzhou & 393.9 & 728.1 & 334.2 & 32.11 & 22.59 & 39.64 & 98.20 \\
Tianjin & 547.0 & 853.6 & 306.6 & 19.92 & 11.07 & 31.00 & 83.16 \\
Chengdu & 323.4 & 562.1 & 238.7 & 32.41 & 25.61 & 37.73 & 99.54 \\
Nanjing & 316.3 & 545.4 & 229.2 & 31.74 & 17.61 & 37.24 & 92.50 \\
Shanghai & 763.3 & 987.3 & 224.0 & 10.75 & 4.07 & 19.40 & 46.23 \\
Zhengzhou & 237.9 & 433.4 & 195.5 & 26.92 & 16.14 & 35.38 & 85.80 \\
Hangzhou & 206.5 & 397.0 & 190.5 & 26.59 & 16.24 & 32.61 & 89.19 \\
Xi'an & 207.4 & 316.3 & 108.8 & 10.88 & 5.14 & 23.45 & 73.43 \\
\hline
\end{tabular}

$\mathrm{C} 1$ - urban area in $1995\left(\mathrm{~km}^{2}\right)$; C2-urban area in $2010\left(\mathrm{~km}^{2}\right)$; C3-increased urban area $\left(\mathrm{km}^{2}\right)$; 4 - median of dNTL; C5-first quartile; C6-third quartile; C7—proportion of pixels with $P$-value $<0.05$ (\%).

\subsection{Threshold Selections of dNTL for Identifying LULC Conversions into Artificial Lands}

On one hand, it is quite reasonable that more salient responses of nighttime lighting signals are typically found in the LULC conversions into artificial lands in which a relatively large average increase in NTL and a large proportion of converted pixels with a statistically significant step change in NTL were usually found. This is mainly because satellite-derived nocturnal luminosity data are particularly sensitive to land surfaces with high-density artificial lighting sources at night, generally in human settlements and built-up areas. On the other hand, the aforementioned marked differences in quantitative responses of NTL to different types of LULC changes could suggest that most LULC 
conversions into artificial lands might be distinguishable through the observed differences in the responses of nighttime lighting signals. Then, a crucial question arises of how to determine the threshold value of changes in NTL for spatial identification of newly emerged man-made surfaces between two observational periods among various types of LULC conversions. In practice, the answer to this question plays a pivotal role in guiding nighttime light data-based investigations of human settlement dynamics, especially for urban expansions. As represented in the above analysis results, there are always a few pixels converted into non-man-made lands and having marked responses in NTL signals in terms of both the statistical significance and the magnitude, primarily because of the diversity and the spatial heterogeneity of human activities, as well as the over-glow effect in nighttime light images. By contrast, a small quantity of pixels converted into artificial surfaces have no visible changes in nighttime light brightness. These findings can jointly state that the nightlight signals-based partition might not completely distinguish the LULC changes into man-made lands and those into non-man-made lands from each other.

As in our previous study [16], we used a receiver operating characteristic (ROC) curve to evaluate the performance of dNTL threshold-based identification rules (a binary partition) in detecting the newly emerged artificial lands among various types of LULC conversions and towards finding an optimal threshold. The ROC curve is generally created by the sensitivity (known as the true positive rate) against the specificity (the true negative rate). Here, the sensitivity measures the proportion of actual LULC conversions from other types into artificial lands that are correctly identified as such. Correspondingly, the specificity is defined as the proportion of LULC conversions into non-artificial lands that are correctly excluded from the partition.

Analyses with two ROC curves were carried out for dNTL threshold-based identifications of newly added artificial lands (including urban, rural, and built-up lands together) and urban lands between 1995 and 2010, separately as displayed in Figure 8a,b. The area under the ROC curve (AUC) provides a quantitative measure of the overall performance of dNTL threshold-based partitions. For this study, the AUC value (with an expected value of 1) can be explained as the probability that a randomly selected pixel with the condition (i.e., its dNTL value is larger than a given threshold) from all converted pixels has the result indicating a greater likelihood of being an actual artificial land in 2010 than that of a randomly chosen pixel without the condition. Here, the AUC value was estimated to be 0.87 for all types of newly added artificial lands (Figure 8a) and 0.89 for emerged urban lands (Figure $8 b$ ). More generally speaking, we might have an overall nearly 90 percent chance of distinguishing newly added artificial lands converted from other types of lands between 1995 and 2010 by using the observed step change in nighttime lighting signals.

As illustrated in Figure 8a, a perfect identification is always located on the top-left point with an expected value of 1 for both measures, the sensitivity and specificity. In our two cases, the optimal threshold of dNTL can be obtained by a trade-off between the sensitivity and specificity using the minimum distance between the point on the ROC curve and the perfect classification point. An optimal dNTL threshold of 4.8 was estimated for the nationwide identification of the LULC conversions into three types of artificial lands (see Figure $8 \mathrm{a}$ ), while $\sim 79.3 \%$ of target DMSP pixels (totally covering $\left.\sim 3.0 \times 10^{4} \mathrm{~km}^{2}\right)$ were included and $\sim 84.1 \%$ of non-target pixels $\left(\sim 9.2 \times 10^{4} \mathrm{~km}^{2}\right)$ were excluded. The majority ( $\sim 95.5 \%)$ of non-target pixels can be precluded as the dNTL threshold is enhanced to 12 . Meanwhile, $\sim 37.4 \%$ of target pixels were also omitted. By contrast, $\sim 87.3 \%$ of target pixels can be identified while the dNTL threshold is deduced to a low value of 2. A large proportion $(\sim 31.1 \%)$ of non-target pixels, however, can also be contained. As shown in Figure $8 b$, the estimated optimal dNTL threshold for identifying the LULC conversions into urban lands is equal to 7.8, while $\sim 86.6 \%$ of nationwide target pixels $\left(\sim 1.5 \times 10^{4} \mathrm{~km}^{2}\right)$ were recognized and $\sim 83.8 \%$ of non-target pixels $\left(\sim 10.7 \times 10^{4} \mathrm{~km}^{2}\right)$ were ruled out. When we increased the dNTL threshold to $12, \sim 87.8 \%$ of non-target pixels and $\sim 21.6 \%$ of target-pixels were ruled out. Although the reduction of the dNTL threshold can apparently result in a marked increase in the sensitivity, a sizeable proportion of non-target pixels might also be included in this case. Hence, given the capability of nighttime light data 
for identification of the LULC conversions into man-made lands, a trade-off between the sensitivity and specificity in the threshold-based partition is crucially important.
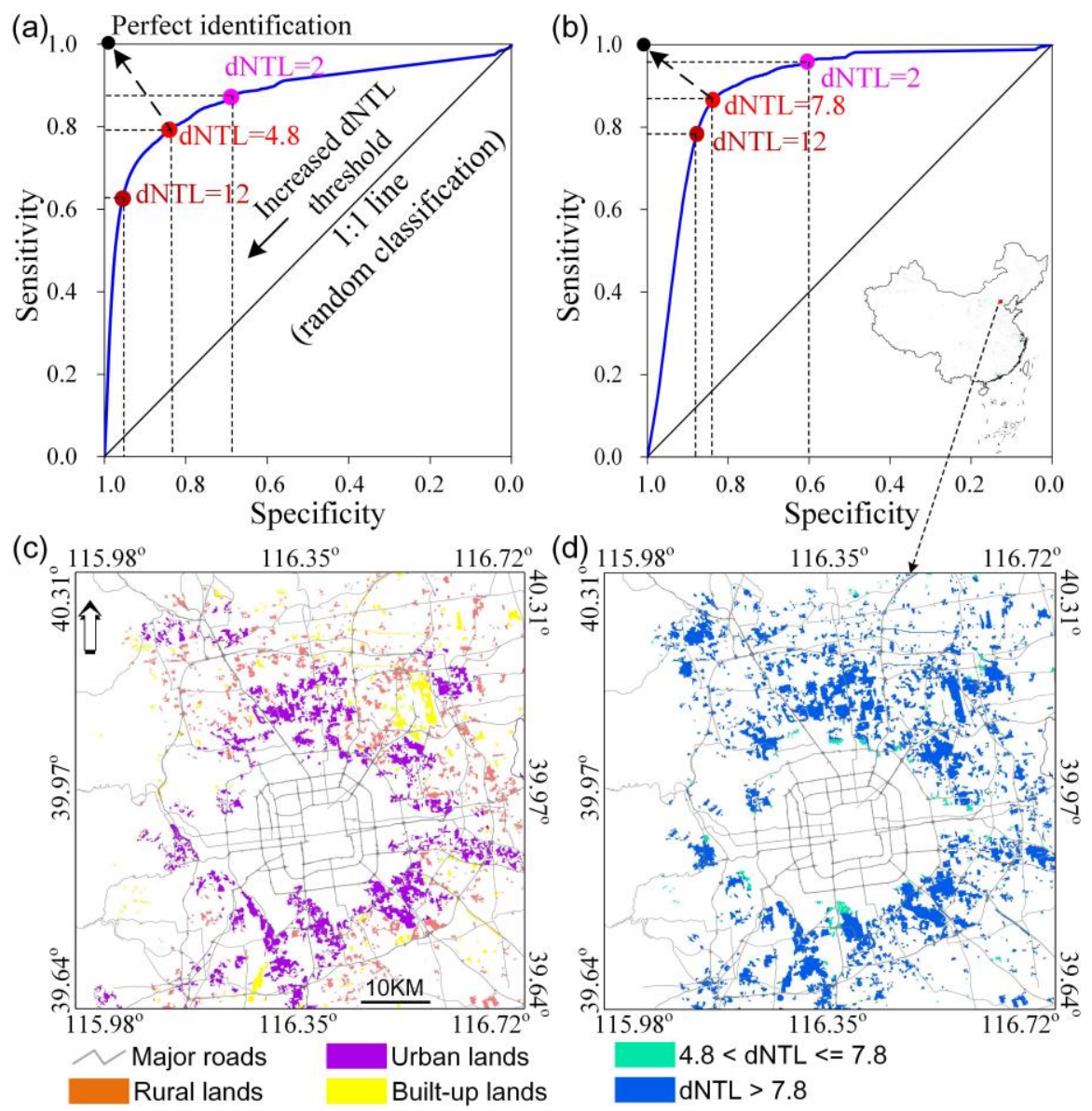

Figure 8. Receiver operating characteristic (ROC) curve-based nationwide threshold selections of dNTL for identifying LULC conversions into artificial lands (a) and urban lands (b). (c) Spatial distributions of newly emerged artificial lands between 1995 and 2010 over Beijing City. (d) The partitioned result based on the step change in nighttime lights according to the optimal dNTL thresholds estimated by the ROC curves in $(\mathbf{a}, \mathbf{b})$.

As exemplified by Beijing City, Figure 8c,d illustrate the spatial distributions of the LULC conversions into urban, rural and built-up lands between 1995 and 2010 and the optimal dNTL threshold-based partitions, respectively. The visible consistency of two distributions over the region might indicate the overall effectiveness of nighttime lighting signals for detecting the spatial expansions of man-made-surfaces during the urbanization process. Moreover, we can find that both the omitted target pixels and included non-target pixels likely occur in the periphery of local hot spots of urbanizing areas, where the capability of nighttime lighting signals is probably limited by both the complexity of human activity and the over-glow effect of DMSP NTL images. Similar results can also be found in other regions like the Yangtze River Delta urban agglomeration and the Pearl River Delta urban agglomeration (see Figure A1). Table A1 gives quantitative comparisons of LULC conversions into artificial and urban lands observed by Landsat-derived LULC maps and identified by optimal DMSP dNTL thresholds across 10 major cities in China.

\section{Conclusions}

The utility of satellite-derived artificial lighting radiances at night for investigations of various types of human activity at multiple scales has been widely addressed. Apart from the capability of 
sensors, the features of remotely sensed nocturnal luminosity images are mainly determined by the spatial distributions of diverse artificial lighting sources on the ground. In the absence of explicit texture information regarding artificial surfaces, it is often very hard to spatially identify diverse human activities and their dynamics at a fine scale merely using the observed magnitude of nighttime light brightness over time and space. Hence, the pixel-level quantitative estimates for both the connections between nighttime light radiances and land-use/land-cover types and the responses of NTL signals to anthropogenic LULC changes are fundamentally important for further uses of nighttime light data, especially in studying the patterns and dynamics of diverse human settlements.

In our previous study [16], we investigated the pixel-level connections of the VIIRS-derived nighttime light image to the LULC dataset (both in 2015) and revealed the notable differences in the NTL signals between man-made surfaces and non-artificial lands. In this study, we further studied the pixel-level quantitative responses of DMSP NTL signals to anthropogenic LULC changes between 1995 and 2010 across China. First, our results represent the high prevalence of distinct changes in NTL signals responding to the LULC conversions into man-made land surfaces. These responses can be quantitatively measured by a step change between two observational periods with the statistical significance test. Second, a minor proportion of the LULC conversions into non-man-made surfaces can also show marked increases in nighttime lights; the magnitude of changes in NTL on average, however, is relatively low. Third, we thus are able to identify the LULC conversions into man-made lands using the step change in nighttime lights with a high chance as estimated by the ROC curve. Finally, an optimal threshold of step change in nighttime light brightness-for detecting newly added artificial lands during the observational period — can be obtained by weighting both the sensitivity and the specificity equally on the ROC curve.

In addition, the relatively coarse spatial resolution and visible over-glow effects in DMSP nighttime light images are likely to cause a large uncertainty with respect to the spatial identifications of artificial land dynamics, especially in the peripheral areas of human settlements and built-up lands. By comparison, the current nighttime light images derived from VIIRS DNB with a higher spatial resolution, a wider radiometric detection range, and a lower over-glow effect can provide us with a detailed look at land surfaces over human settlements. Whether the quantitative response of VIIRS DNB NTL signals to anthropogenic LULC changes can be beneficial for identification of artificial land dynamics should be investigated in future studies, while the long-term archives of VIIRS DBN nightlight data (especially the annual composite product) become available. Such investigations are quite important for the increasing uses of satellite-derived nocturnal luminosity data, particularly in the context of the uncertainty and mis-specification in nighttime light data-related results and applications.

Author Contributions: T.M. conceived and designed the study and methods; T.M. analyzed the data; T.M. wrote the paper.

Funding: This study was funded by the National Natural Science Foundation of China (Nos. 41590845, 41771418, 41421001), the Key Research Program of Frontier Science, Chinese Academy of Sciences (No. QYZDY-SSW-DQC007), the National Science and Technology Key Project (No. 2016YFB0502301), and the National Key Basic Research Program of China (No. 2015CB954101).

Acknowledgments: The author would like to thank Xinliang $\mathrm{Xu}$ for providing the land-use/land-cover datasets. We would also like to extend our thanks to all the reviewers for their helpful comments and suggestions.

Conflicts of Interest: The author declares no conflict of interest. 


\section{Appendix A}

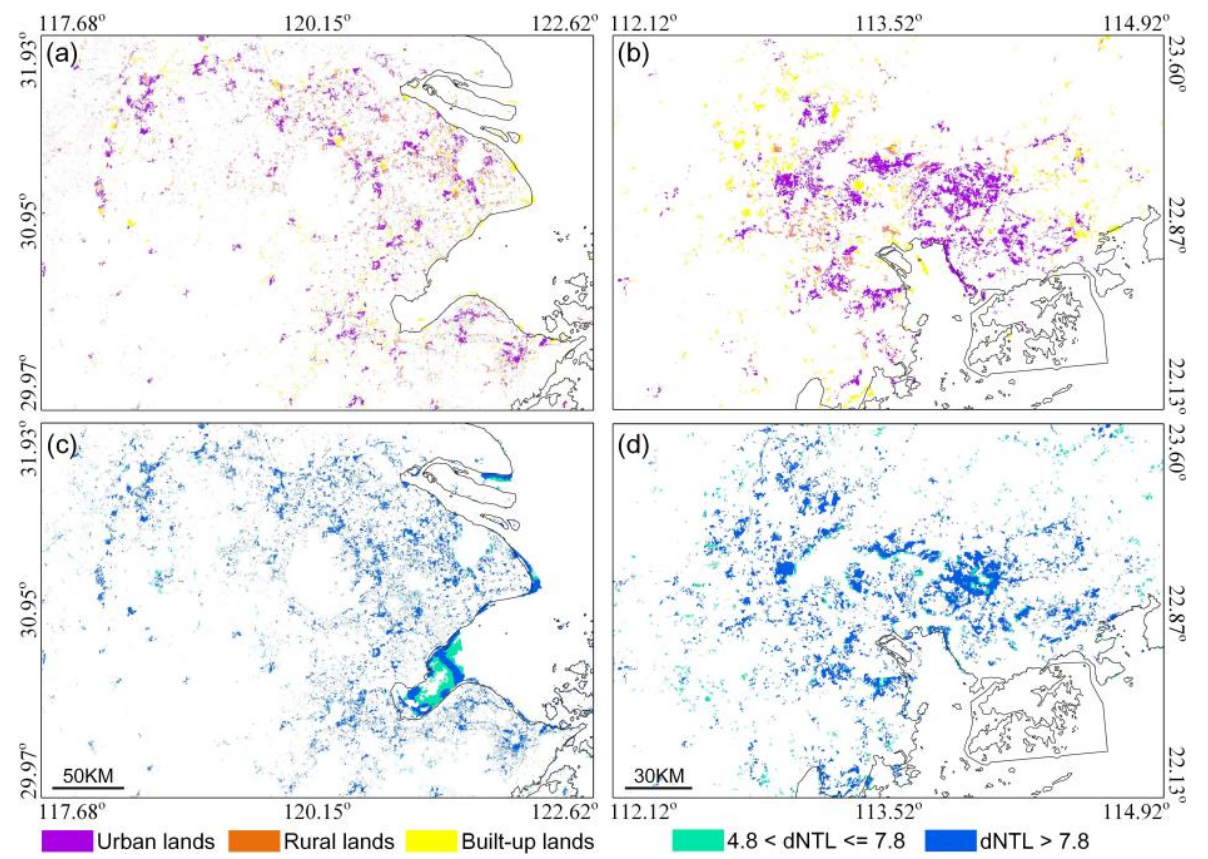

Figure A1. Spatial distributions of newly emerged artificial lands between 1995 and 2010 over (a) the Yangtze River Delta urban agglomeration and (b) the Pearl River Delta urban agglomeration. The partitioned result based on the step change in nighttime lights according to the optimal dNTL thresholds over (c) the Yangtze River Delta urban agglomeration and (d) the Pearl River Delta urban agglomeration.

Table A1. Summary of optimal dNTL threshold-based identifications of LULC conversions into artificial and urban land areas (in $\mathrm{km}^{2}$ ) between 1995 and 2010 across 10 major cities in China.

\begin{tabular}{ccccccccc}
\hline & C1 & C2 & C3 & C4 & C5 & C6 & C7 & C8 \\
\hline Guangzhou & 8152.1 & $13,398.8$ & 5246.7 & 4486.4 & 403.3 & 806.1 & 402.8 & 271.9 \\
Beijing & $21,937.4$ & $27,837.2$ & 5899.8 & 5293.5 & 1017.0 & 1404.6 & 387.6 & 329.6 \\
Suzhou & 8647.6 & $17,044.4$ & 8396.8 & 8402.6 & 393.9 & 728.1 & 334.2 & 326.6 \\
Tianjin & $18,159.6$ & $22,979.3$ & 4819.7 & 4653.3 & 547.0 & 853.6 & 306.6 & 255.6 \\
Chengdu & $11,089.1$ & $14,973.2$ & 3884.1 & 3851.2 & 323.4 & 562.1 & 238.7 & 238.1 \\
Nanjing & 9394.0 & $13,910.8$ & 4516.8 & 4109.5 & 316.3 & 545.4 & 229.2 & 207.3 \\
Shanghai & $13,748.6$ & $21,615.8$ & 7867.2 & 6890.7 & 763.3 & 987.3 & 224.0 & 134.8 \\
Zhengzhou & 8067.0 & $10,702.5$ & 2635.5 & 2456.7 & 237.9 & 433.4 & 195.5 & 174.2 \\
Hangzhou & 5025.2 & 8441.6 & 3416.4 & 3243.6 & 206.5 & 397.0 & 190.5 & 172.6 \\
Xi'an & 7834.1 & 9253.4 & 1419.3 & 1063.7 & 207.4 & 316.3 & 108.8 & 67.8
\end{tabular}

C1-artificial land area (including urban, rural and built-up lands together) in 1995; C2-artificial land area in 2010; C3 - increased artificial land area; C4—increased artificial land area with dNTL > 4.8 according to Figure 8a; C5-urban area in 1995; C6 - urban area in 2010; C7-increased urban area; C8-increased urban area with dNTL $>7.8$ according to Figure 8 b.

\section{References}

1. Sutton, P.C. A scale-adjusted measure of "urban sprawl" using nighttime satellite imagery. Remote Sens. Environ. 2003, 86, 353-369. [CrossRef]

2. Doll, C.; Muller, J.; Morley, J. Mapping regional economic activity from night-time light satellite imagery. Ecol. Econ. 2006, 57, 75-92. [CrossRef]

3. Ghosh, T.; Powell, R.L.; Elvidge, C.D.; Baugh, K.E.; Sutton, P.C.; Anderson, S. Shedding light on the global distribution of economic activity. Open Geogr. J. 2010, 3, 148-161. 
4. Chen, X.; Nordhaus, W.D. Using luminosity data as a proxy for economic statistics. Proc. Natl. Acad. Sci. USA 2011, 108, 8589-8594. [CrossRef] [PubMed]

5. Zhang, Q.; Seto, K.C. Mapping urbanization dynamics at regional and global scales using multi-temporal DMSP/OLS nighttime light data. Remote Sens. Environ. 2011, 115, 2320-2329. [CrossRef]

6. Small, C.; Elvidge, C.D. Mapping decadal change in anthropogenic night light. Procedia Environ. Sci. 2011, 7, 353-358. [CrossRef]

7. Li, X.; Ge, L.; Chen, X. Detecting Zimbabwe's decadal economic decline using nighttime light imagery. Remote Sens. 2013, 5, 4551-4570. [CrossRef]

8. Kyba, C.C.M.; Kuester, T.; Sánchez de Miguel, A.; Baugh, K.; Jechow, A.; Hölker, F.; Bennie, J.; Elvidge, C.D.; Gaston, K.J.; Guanter, L. Artificially lit surface of Earth at night increasing in radiance and extent. Sci. Adv. 2017, 3, e1701528. [CrossRef] [PubMed]

9. Bennett, M.M.; Smith, L.C. Advances in using multitemporal night-time lights satellite imagery to detect, estimate, and monitor socioeconomic dynamics. Remote Sens. Environ. 2017, 192, 176-197. [CrossRef]

10. Small, C.; Sousa, D.; Yetman, G.; Elvidge, C.; MacManus, K. Decades of urban growth and development on the Asian megadeltas. Glob. Planet. Chang. 2018, 165, 62-89. [CrossRef]

11. Sutton, P.; Roberts, D.; Elvidge, C.; Baugh, K. Census from heaven: An estimate of the global human population using night-time satellite imagery. Int. J. Remote Sens. 2001, 22, 3061-3076. [CrossRef]

12. Small, C.; Pozzi, F.; Elvidge, C.D. Spatial analysis of global urban extent from DMSP/OLS night lights. Remote Sens. Environ. 2005, 96, 277-291. [CrossRef]

13. Elvidge, C.; Baugh, K.; Anderson, S.; Sutton, P.; Ghosh, T. The night light development index (NLDI): A spatially explicit measure of human development from satellite. Soc. Geogr. 2012, 7, 23-35. [CrossRef]

14. Huang, Q.; Yang, X.; Gao, B.; Yang, Y.; Zhao, Y. Application of DMSP/OLS nighttime light images: A meta-analysis and a systematic literature review. Remote Sens. 2014, 6, 6844-6866. [CrossRef]

15. Li, X.; Li, D.; Xu, H.; Wu, C. Intercalibration between DMSP/OLS and VIIRS night-time light images to evaluate city light dynamics of Syria's major human settlement during Syrian Civil War. Int. J. Remote Sens. 2017, 38, 5934-5951. [CrossRef]

16. Ma, T. An estimate of the pixel-Level connection between Visible Infrared Imaging Radiometer Suite Day/Night Band (VIIRS DNB) nighttime lights and land features across China. Remote Sens. 2018, 10, 723. [CrossRef]

17. Elvidge, C.D.; Baugh, K.E.; Kihn, E.A.; Kroehl, H.W.; Davis, E.R. Mapping city lights with nighttime data from the DMSP Operational Linescan System. Photogramm. Eng. Remote Sens. 1997, 63, 727-734.

18. Hillger, D.; Kopp, T.; Lee, T.; Lindsey, D.; Seaman, C.; Miller, S.; Solbrig, J.; Kidder, S.; Bachmeier, S.; Jasmin, T. First-light imagery from Suomi NPP VIIRS. Bull. Am. Meteorol. Soc. 2013, 94, 1019-1029. [CrossRef]

19. Elvidge, C.D.; Baugh, K.E.; Zhizhin, M.; Hsu, F.-C. Why VIIRS data are superior to DMSP for mapping nighttime lights. Proc. Asia-Pac. Adv. Netw. 2013, 35, 62-69. [CrossRef]

20. Elvidge, C.D.; Baugh, K.; Zhizhin, M.; Hsu, F.-C.; Ghosh, T. VIIRS night-time lights. Int. J. Remote Sens. 2017, 38, 5860-5879. [CrossRef]

21. Falchi, F.; Cinzano, P.; Duriscoe, D.; Kyba, C.C.; Elvidge, C.D.; Baugh, K.; Portnov, B.A.; Rybnikova, N.A.; Furgoni, R. The new world atlas of artificial night sky brightness. Sci. Adv. 2016, 2, e1600377. [CrossRef] [PubMed]

22. Amaral, S.; Câmara, G.; Monteiro, A.M.V.; Quintanilha, J.A.; Elvidge, C.D. Estimating population and energy consumption in Brazilian Amazonia using DMSP night-time satellite data. Comput. Environ. Urban Syst. 2005, 29, 179-195. [CrossRef]

23. Li, X.; Xu, H.; Chen, X.; Li, C. Potential of NPP-VIIRS nighttime light imagery for modeling the regional economy of China. Remote Sens. 2013, 5, 3057-3081. [CrossRef]

24. Shi, K.; Yu, B.; Huang, Y.; Hu, Y.; Yin, B.; Chen, Z.; Chen, L.; Wu, J. Evaluating the ability of NPP-VIIRS nighttime light data to estimate the gross domestic product and the electric power consumption of China at multiple scales: A comparison with DMSP-OLS data. Remote Sens. 2014, 6, 1705-1724. [CrossRef]

25. Shi, K.; Huang, C.; Yu, B.; Yin, B.; Huang, Y.; Wu, J. Evaluation of NPP-VIIRS night-time light composite data for extracting built-up urban areas. Remote Sens. Lett. 2014, 5, 358-366. [CrossRef]

26. Ma, T.; Zhou, Y.; Zhou, C.; Haynie, S.; Pei, T.; Xu, T. Night-time light derived estimation of spatio-temporal characteristics of urbanization dynamics using DMSP/OLS satellite data. Remote Sens. Environ. 2015, 158, 453-464. [CrossRef] 
27. Yu, B.; Shi, K.; Hu, Y.; Huang, C.; Chen, Z.; Wu, J. Poverty evaluation using NPP-VIIRS nighttime light composite data at the county level in China. IEEE J. Sel. Top. Appl. Earth Obs. Remote Sens. 2015, 8, 1217-1229. [CrossRef]

28. Jing, X.; Shao, X.; Cao, C.; Fu, X.; Yan, L. Comparison between the Suomi-NPP Day-Night Band and DMSP-OLS for correlating socio-economic variables at the provincial level in China. Remote Sens. 2016, 8, 17. [CrossRef]

29. Sharma, R.C.; Tateishi, R.; Hara, K.; Gharechelou, S.; Iizuka, K. Global mapping of urban built-up areas of year 2014 by combining MODIS multispectral data with VIIRS nighttime light data. Int. J. Digit. Earth 2016, 9, 1004-1020. [CrossRef]

30. Levin, N.; Zhang, Q. A global analysis of factors controlling VIIRS nighttime light levels from densely populated areas. Remote Sens. Environ. 2017, 190, 366-382. [CrossRef]

31. Dou, Y.; Liu, Z.; He, C.; Yue, H. Urban land extraction using VIIRS nighttime light data: An Evaluation of Three Popular Methods. Remote Sens. 2017, 9, 175. [CrossRef]

32. Zhao, N.; Hsu, F.-C.; Cao, G.; Samson, E.L. Improving accuracy of economic estimations with VIIRS DNB image products. Int. J. Remote Sens. 2017, 38, 5899-5918. [CrossRef]

33. Zheng, Q.; Deng, J.; Jiang, R.; Wang, K.; Xue, X.; Lin, Y.; Huang, Z.; Shen, Z.; Li, J.; Shahtahmassebi, A.R. Monitoring and assessing "ghost cities" in Northeast China from the view of nighttime light remote sensing data. Habitat Int. 2017, 70, 34-42. [CrossRef]

34. Ma, T.; Yin, Z.; Zhou, A. Delineating spatial patterns in human settlements using VIIRS nighttime light data: A watershed-based partition approach. Remote Sens. 2018, 10, 465. [CrossRef]

35. Lu, D.; Tian, H.; Zhou, G.; Ge, H. Regional mapping of human settlements in southeastern China with multisensor remotely sensed data. Remote Sens. Environ. 2008, 112, 3668-3679. [CrossRef]

36. Zhang, Q.; Schaaf, C.; Seto, K.C. The vegetation adjusted NTL urban index: A new approach to reduce saturation and increase variation in nighttime luminosity. Remote Sens. Environ. 2013, 129, 32-41. [CrossRef]

37. Ma, T.; Xu, T.; Huang, L.; Zhou, A. A human settlement composite index (HSCI) derived from nighttime luminosity associated with imperviousness and vegetation indexes. Remote Sens. 2018, 10, 455. [CrossRef]

38. Liu, J.; Liu, M.; Tian, H.; Zhuang, D.; Zhang, Z.; Zhang, W.; Tang, X.; Deng, X. Spatial and temporal patterns of China's cropland during 1990-2000: An analysis based on Landsat TM data. Remote Sens. Environ. 2005, 98, 442-456. [CrossRef]

39. Liu, J.; Kuang, W.; Zhang, Z.; Xu, X.; Qin, Y.; Ning, J.; Zhou, W.; Zhang, S.; Li, R.; Yan, C.; et al. Spatiotemporal characteristics, patterns, and causes of land-use changes in China since the late 1980s. J. Geogr. Sci. 2014, 24, 195-210. [CrossRef]

40. Elvidge, C.D.; Ziskin, D.; Baugh, K.E.; Tuttle, B.T.; Ghosh, T.; Pack, D.W.; Erwin, E.H.; Zhizhin, M. A fifteen year record of global natural gas flaring derived from satellite data. Energies 2009, 2, 595-622. [CrossRef]

41. Liu, Y.; Liu, Y.; Chen, Y.; Long, H. The process and driving forces of rural hollowing in China under rapid urbanization. J. Geogr. Sci. 2010, 20, 876-888. [CrossRef]

42. Long, H. Land consolidation: an indispensable way of spatial restructuring in rural China. J. Geogr. Sci. 2014, 24, 211-225. [CrossRef]

(C) 2018 by the author. Licensee MDPI, Basel, Switzerland. This article is an open access article distributed under the terms and conditions of the Creative Commons Attribution (CC BY) license (http://creativecommons.org/licenses/by/4.0/). 